\title{
Why Business Firms Have Moral Obligations to Mitigate Climate Change
}

\author{
Anne Schwenkenbecher
}

\section{Introduction}

Climate change is a collective action problem. It is the result of an infinite number of individual and collective human actions and it can only be addressed by the concerted efforts of governments, organisations and individuals across the globe.

The projected consequences of climate change will—and to some extent already do-have a negative impact on human wellbeing and the natural environment. It is widely agreed that climate change is an ethical problem. Climate change harms people, making current and future generations worse off than they could have been.

One of the required responses to climate change is mitigation: this includes taking measures to limit global warming to a maximum of $2{ }^{\circ} \mathrm{C}$. And one of the key aspects of mitigation is the reduction of greenhouse gas (GHG) emissions.

There is general consensus that states should be the main drivers of climate change mitigation and governments around the world should cooperate with one another in order to achieve the required reduction in GHG emissions, stop deforestation, etc. It is also widely acknowledged that the world is not currently on track to reducing its emissions enough to have a significant chance of limiting global warming to $2{ }^{\circ} \mathrm{C}$ and that mitigation efforts must go beyond current pledges (UNEP 2015).

In the light of the urgency of the problem and the fact that aggregate action-the sum of many individual actions - can actually make a significant difference to the problem (Dietz et al. 2009) voluntary efforts by agents other than state governments are clearly desirable and arguably morally mandatory. That is, such agents may well be morally required to do more than what the law demands of them.

\footnotetext{
A. Schwenkenbecher $(\square)$

School of Arts, Murdoch University, Perth, WA, Australia

e-mail: a.schwenkenbecher@murdoch.edu.au
} 
Elsewhere, I have argued that individual agents have an obligation to reduce their carbon footprint (Schwenkenbecher 2014). In this chapter, I argue that we have even more reason to ascribe obligations to reduce GHG emissions to business firms and corporations (in the following called 'businesses' or 'firms').

To many people it is intuitively plausible to suggest that businesses have such obligations, others would reject this idea. This chapter will address three potential counter-arguments against the view that business firms have such obligations: (i) the view that firms are not moral agents and as such cannot hold moral obligations; (ii) the view that their principal obligation is towards their shareholders or owners; and (iii) the view that they cannot have such obligations since no individual business's actions would make a significant difference to global warming.

One underlying assumption of this investigation is that businesses as entities are distinct from the individual agents composing them. In other words, a business firm is something over and above the individual(s) composing it. As such, if an organisation can be shown to have moral agency then it can have moral obligations qua organisation. The individuals composing the organisation then have-differentmoral obligations qua being members of that organisation.

Further, the relative strength of these obligations would depend on agents' capacities to discharge them and arguably on their direct or indirect causal contributions to the harm that is climate change as well as their relative ability to make a positive impact on mitigation. This chapter will first address the larger question of whether or not businesses are appropriate addressees of such obligations per se, and then turn to the question of differentiated responsibilities.

Another underlying assumption is that swift action is not only necessary in order to limit global warming and climatic change, but morally crucial. The moral obligations identified in this article should be understood as pro tanto obligations, that is, obligations that can be overridden and outweighed by other relevant moral obligations. Furthermore, while climate change mitigation encompasses a range of actions and measures, the focus of this discussion will be on reducing GHG only.

\section{Business Firms as Moral Agents}

Can business firms and corporations be appropriate addressees of moral obligations? Or, more generally, can groups with a certain organisational structure be moral agents?

The following is the most obvious objection to such a view: in order to have agency, let alone moral agency, an entity must be capable of having intentional states and only beings with brains and minds are capable of having intentions proper. Therefore, so the objection goes, in an organised group such as a business firm, the only agents are individual human beings, even if we tend to ascribe agency and sometimes moral responsibility, obligations or blame to the group as a whole as a shorthand. 
Many of those who defend the possibility of group agency would argue that a group of agents - if it has the right kind of structure-is capable of forming groupbased 'representational and goal-seeking states' such as beliefs, desires, judgments or plans, which play the same role as individual intentions do for individual human agents. On such functionalist accounts of intentionality, group agents can have group-level intentions, which, while they may differ from those intentions individual agents have, play the same functional role as the former. ${ }^{1}$ Whether they can be said to have such intentions, according to List and Pettit (2011), depends on whether they abide by standards of rationality such as consistency and deductive closure.

It is the fact that functionalists about group intentions largely operate within the parameters of agency individualism that makes their view particularly attractive (since it is in keeping with the dominant philosophical approach to agency) and more so than collectivist views according to which a group can have a mind of its own quite distinct from the minds of the individuals composing it.

On List and Pettit's (2006: 87) account, a group agent proper acts or intervenes in the world on the basis of the representational and goal-seeking states it has formed, abiding by conditions of rationality "not just accidentally or contingently, but robustly". In order to arrive at group judgments, an organization must have a constitution: "a set of rules, formal or informal for determining how the inputs of individuals are to be put together to generate group judgments as outputs" (List and Pettit's 2006: 89). Groups that lack such a constitution, on this account, cannot form group judgments and therefore cannot act as a group. Group judgments supervene on individual judgments: the former are caused by the latter, but are not reducible to them. ${ }^{2}$

But even if we grant that groups are agents in a sense that is relevantly similar to individual agents, what about moral agency? We usually consider only those moral agents who are capable of acting on the basis of moral principles or moral reasons. This entails that they are capable of fully understanding moral principles and reasons. Hence, we generally do not consider young children, demented persons or animals capable of moral agency, even if we consider them agents.

According to List and Pettit (2011: 158), a group agent is fit to be held responsible for doing something to the extent that it satisfies these requirements:

1. The group agent faces a normatively significant choice, involving the possibility of doing something good or bad, right or wrong.

2. The group agent has the understanding and access to evidence required for making normative judgments about the options.

\footnotetext{
${ }^{1}$ List and Pettit write that: "We make no assumptions about the precise physical nature of intentional states. They may be of a wide variety of kinds. ... We only require that hey be configurations of the agent ... that play the appropriate functional role." (2011:21).

${ }^{2}$ It should perhaps be noted that List and Pettit's account of group agency is modelled on business corporations, less so on small firms or family businesses. However, there is no reason why the latter should not display the same level of group rationality and intentions as a corporation.
} 
3. The group agent has the control required for choosing between the options.

The first requirement is uncontroversial. Clearly, group agents such as corporations can and do constantly face morally significant choices. The third requirement may equally seem uncontroversial-we do usually assume that firms, organizations, states, etc. are in control of their choices. ${ }^{3}$ The second requirement, however, may well seem controversial since it suggests that corporations would 'understand' what it means to take one or the other option, and to make morally relevant choices. Yet, the way in which a group agent understands the moral significance of choices would be different from how an individual agent understands these. What is meant here is the following:

Since the members of any group are able to form judgments on normative propositions in their individual lives, there is no principled reason why they should not be able to propose such propositions for group consideration and resolution-that is, for inclusion in the group's agenda. (List and Pettit 2011: 159)

Since List and Pettit's account of group agency is ultimately based on an individualist (though not reductionist) notion of agency and intentionality, it is the group member's ability to form an understanding of the moral relevance of options faced by the group and further their ability to use this understanding as input into the group's decision making, which make it possible for the 'group' to have an understanding of normative implications of its decisions and actions. If the group members are not able to bring normative reasons into the group decision making process then the group will lack moral understanding and moral agency.

I have mainly relied on List and Pettit's account of group agency so far. Therefore, let me briefly point to other scholars defending the view that groups can be moral agents. Peter French argued as early as 1984 that corporations are fully-fledged moral persons (French 1984), a view extended by Toni Erskine (2001) to cover states. Erskine in fact argues that structured group agents "enjoy greater capacities for deliberation and action than are enjoyed by individuals" (2001: 73). They can therefore have greater potential to promote social goods or violate moral constraints than individual agents (ibid.). James Dempsey went even further by arguing that any 'morally significant system', "that is a non-agential system created by moral agents" can be held morally responsible — not just agents themselves (Dempsey 2013). It is fair to say that the view that incorporated group agents are in principle capable of moral agency is increasingly accepted amongst moral philosophers, while more radical views such as James Dempsey's are much more controversial.

\footnotetext{
${ }^{3}$ Admittedly, there is some controversy around this issue, but I am not able to discuss it here. Existing discussions include List, Christian, and Philip Pettit. 2011. Group Agency: The Possibility, Design, and Status of Corporate Agents. Oxford; New York: Oxford University Press, chapter 6 and pp. 159-163, “The control desideratum”, Strand, A. (2013). "Group Agency, Responsibility, and Control.” Philosophy of the Social Sciences 43(2): 201-224; Szigeti, A. (2014). Collective Responsibility and Group-Control. Rethinking the Individualism-Holism Debate. J. Zahle and F. Collin, Springer: 97-116.
} 


\section{Business Firms' Obligations to Stakeholders}

Even if one accepts the view that business firms can have moral obligations (or responsibilities-I will use these terms synonymously) as such, it does not follow that they have obligations to contribute to climate change mitigation beyond what is legally required of them. Three different views concerning the moral obligations of business firms to reduce GHG emissions can be distinguished.

The first view is that a business firm's sole obligation is to its stakeholders and to increase its profits. Note that this view does not allow for firms to hold obligations with regard to climate change mitigation, unless these increase the firm's profit. Further, on this view it is morally wrong of a firm to dedicate funds towards any end, which does not increase its profits. ${ }^{4}$

The second view is that the primary obligation of business firms is to generate a profit for their owners or shareholders, but that they may have other obligations, too. While the obligation to increase profits weighs heavier than all other obligations it may be overridden should various other moral concerns speak against it. Further, where profits are not significantly affected, business firms have moral obligations towards people other than their shareholders, namely other stakeholders, that is, all those affected by the actions of the company: individuals, the community it is embedded in and society at large. I think it is this second view which most closely resembles the idea of corporate social responsibility as it is usually conceived.

The third view is that business firms, like any other moral agent, have a variety of (pro tanto ${ }^{5}$ ) obligations, which need to be balanced against one another depending on the circumstances. The obligation a business firm has towards its owners or stakeholders is one consideration amongst many. In particular, the obligation to make a profit and to further the interests of owners and shareholders cannot override fundamental normative imperatives. According to philosopher Robert Solomon (1991: 364), whom I consider to be a proponent of this view, "when the demands of doing business conflict with morality or wellbeing in society, it is business that has to yield".

According to both the second and the third views, business firms can have moral obligations to contribute to climate change mitigation beyond what is legally required of them. The difference between the two views is one of degree and I will not further distinguish between them. Instead, my main concern is to illustrate what may be wrong with the first view and why we may have good reason to abandon it. The idea that a business firm's primary objective is to make a profit and

\footnotetext{
${ }^{4}$ Another possible option is the view that different rules apply to business operations than to the actions of moral agents generally or that 'ordinary' ethical rules do not apply to business. For a rebuttal of this view see Frederick (2014: 193ff).

${ }^{5}$ An obligation is pro tanto when it delivers a moral reason for a certain cause of action, but not necessarily conclusive moral reason for that action. A pro tanto obligation is not an 'all things considered' obligation, but one which can be overridden by other concerns.
} 
its sole obligation is to the owners or shareholders has long been considered by many to express the dominant understanding of the nature of business operations. It was prominently expressed by Milton Friedman in his now (in)famous article in The New York Times "The Social Responsibility of Business Is to Increase Its Profits" (1970).

According to Solomon, this so-called profit motive is a powerful myth, a useful fiction, which does "obscure rather than clarify the underlying ethos that makes business possible" and which is due to a misunderstanding of business activity as such; "the very idea of 'the profit motive' as an end in itself . . is a serious obstacle to understanding the rich tapestry of motives and activities that make up the business world". Instead, we should think of the social embeddedness of business operations and think about profits "in larger context of productivity and social responsibility". This means that we ought not to single out profits as the central aim of business activity; "they are not as such the end of goal of business activity" (1991: 356-357).

Solomon considers atomistic individualism to be a main culprit of such a reductive notion of firms' ends: the view that business life consists of mutually agreed-upon transactions between (isolated) individual citizens. This view is problematic, since business as a social practice "takes place in a culture with an established set of procedures and expectations". According to Solomon, "[b]usiness life is first of all fundamentally co-operative" and requires shared interests and mutually agreed-upon rules of conduct; its "purpose is to serve the public" (1991: 358).

Following Solomon's argument, we can see that, like any other agent, business firms can only operate within shared social contexts and their actions impact on those who they share this social world with: individuals, other firms and organisations, and even states. There is simply no good reason to exempt business firms from the network of mutual obligations and responsibilities (and privileges or rights) that connects all moral agents. Except, of course, if we claim that business firms are not moral agents per se, a view the plausibility of which I hope to have significantly weakened in the first part of this chapter.

Along similar lines to Solomon, philosopher Robert E. Frederick (2014) argues that business is not possible without its participants' general abidance by 'ordinary' moral rules. Views such as Friedman's ignore that the very basis for the success of business activities is a climate of abidance by general ethical principles:

Business could not operate unless most businesspeople were fair, honest, and trustworthy. Business transactions could not efficiently occur unless the parties to the transaction could count on each other to tell the truth, keep commitments and honor contracts. Without a shared social context of ethical values, assumptions, and understandings, business as we know it would be impossible (2014: 201).

Business scholar R. Edward Freeman (2014: 185) points out that there has been significant legal acknowledgement over the last decades of the need to constrain shareholders' interests where it comes at the expense of other stakeholders. This reflects a need to reconceptualize what business firms are, and ask ourselves "(f)or whose benefit and at whose expense should the firm be managed?". 
Freeman gives a further important reason for holding firms accountable to ethical standards: he argues that the kind of view defended by Milton Friedman relies on the idea of the 'invisible hand', the view first expressed by Adam Smith that no or little government intervention in the conduct of market transactions is ultimately best for all (Smith 1970 [1776]; Narveson 2003). However, according to Freeman this has led to 'tragedy of the commons' problems-common resources such as clean air, water and soil are being depleted or deteriorate, because on the shareholder model no one has responsibility for looking after them. This model therefore makes all of us worse off. What is needed, among other considerations, is the adoption of ecological principles that firms must abide by (2014: 189): corporations ought to be governed "in accordance with the principle of caring for the earth".

In sum, there are good reasons to reject the view that business' sole obligation is to generate profits for its owners or shareholders ${ }^{6}$ and to endorse the view according to which business firms' are merely one kind of agent in the wider moral community.

\section{Two Challenges}

Let us suppose you are in agreement with my argument so far. You agree that climate change mitigation is morally mandatory and that we ought to collectively reduce global GHG emissions. You also agree that business firms can be moral agents that can hold responsibilities and obligations provided they are structured in the right way. And suppose you are convinced that these obligations extend beyond the obligations they have towards their shareholders.

You may still be reluctant to accept the view that business firms have mitigationrelated duties for two reasons:

(i) Negative duties only: You may think that business firms can only hold negative obligations, that is, obligations not to harm, rather than positive obligations to improve states of affairs that they have not caused.

(ii) No difference-maker: Or you may think that whatever any individual business does will not make a difference to the desired level of GHG concentration in the atmosphere. If too few actors (including other businesses) change their harmful practices and reduce their emissions, an individual firm's efforts will be in vain.

I will address both arguments in turn.

\footnotetext{
${ }^{6}$ For a different kind of argument against Friedman see Frederick (2014: 196ff).
} 


\subsection{Business Firms Have Negative Duties Only}

According to the first objection, business firms and their managers must abide by only the most fundamental and stringent moral rules, but need not go beyond these. ${ }^{7}$ In other words, they ought to adhere to so-called negative duties only, but need not discharge positive duties.

Let me briefly explain the difference between these types of duties. Moral philosophers generally distinguish between so-called negative and so-called positive obligations and the latter are often thought to be less stringent and less demanding than the former. ${ }^{8}$

Generally speaking, negative duties are duties to refrain from acting in ways that interfere with others' rights or are harmful to them. Quintessential negative duties are the duty to abide by a principle not to kill or physically harm others, not to steal from others, not to rape them, torture them, etc.

Positive duties usually concern actions (or omissions) that make others better off, even if we are not responsible for the problem they may face. Typical cases triggering positive duties are rescue or assistance scenarios; even if we are not responsible for an elderly gentleman's fall in the middle of a busy intersection, if we witness it and are nearby (and if we do not have more weighty competing obligations) then we are required to assist him. Similarly, we are usually considered to have positive obligations to assist those struck by natural disaster, who, having lost their homes and livelihoods, cannot help themselves and rely on donations and support by others.

According to the first objection, business firms must only abide by principles such as the harm principle; they must not make others worse off for no good reason. But they need not make an active effort to effect positive change in the world. In other words, it is not the duty of companies to make the world a better place, but the duty of governments and government organisation. On this view, business firms are different kinds of moral agents than individuals (or states).

\footnotetext{
${ }^{7}$ Frederick (2014: 211) thinks that Friedman's view is motivated by the worry that morality would demand much more than that from firms. Norman Bowie adheres to the view that businesses have only minimum moral obligations to avoid harm by adhering to environmental laws. However, he grants that they also have an obligation not to interfere with the political process of establishing stringent environmental legislation (Bowie 2014). Morality, Money, and Motor Cars. Business Ethics: readings and cases in corporate morality. W. M. Hoffman, R. Frederick and M. S. Schwartz. Chichester, West Sussex, Wiley-Blackwell: 514-520.

${ }^{8}$ For instance, William Frankena distinguishes between obligations to inflict no evil or harm, prevent evil or harm, remove evil and do or promote good (1973: 47), in a descending order of stringency. It should be noted, however that not all philosophers agree with the moral difference between negative and positive duties and the lesser stringency of the latter compared to the former (Frankena, W. K. (1973). Ethics. Englewood Cliffs, N.J, Prentice-Hall.)
} 
How can we address the first challenge to mitigation-related obligations of firms? Two lines of rebuttal are possible:

(a) One may doubt whether business firms only have negative duties, or else

(b) One may doubt that mitigation-related duties are in fact positive duties.

As to (a): While I cannot address this point here in any detail, there is no obvious reason for assuming that business firms are fundamentally different moral agents from individuals or states - agents, which are generally thought to hold positive moral duties. In other words, the burden of proof for showing that business firms cannot hold positive duties would lie with those who make such a claim.

As to (b): Still, we might wonder whether our obligations to reduce GHG emissions are negative obligations to refrain from harming or positive obligations (e.g. to assist those in need)? The answer to these questions is less straightforward than might be thought at first glance.

The first problem for framing mitigation duties as negative duties is that GHG emissions are not harmful per se. They are harmful in aggregation as opposed to being intrinsically harmful (that is, harmful by themselves, like actions such as killing, maiming, etc.) (Lichtenberg 2010; Schwenkenbecher 2014). This means that no individual agent's emissions and emission-producing activities are harmful if taken by themselves. However, philosophers like Derek Parfit (1984: 70-82) have argued that the effects of individual contributions to aggregate harms, however tiny or imperceptible in isolation, must not be ignored since together they have the potential to greatly harm other people (pp.). Parfit (1984: 83) claims that:

[w]e should cease to think that an act cannot be wrong, because of its effects on other people, if this act makes no one perceptibly worse off. Each of our acts may be very wrong, because of its effects on other people, even if none of these people could ever notice any of these effects. Our acts may together make these people very much worse off.

Consequently, the emission-generating actions of individual agents and of individual business firms may well be considered harmful and are therefore actions in violation of negative duties. This means that taking action to mitigate climate change (be it by reducing one's own carbon footprint or by contributing to mitigating measures in other forms) is a way of complying with one's negative duties, rather than one's positive duties. It is a way of preventing or limiting harm. ${ }^{9}$

Much more could be said at this point about the difference between luxury emissions and subsistence emissions and the fact that emitting GHG is an inevitable feature of human existence-something we cannot avoid doing simply by virtue of being alive. To what extent an agent-collective or individual-is obligated to contribute to climate change mitigation would also depend greatly on their contribution to the problem (polluter-pays principle) and their ability to affect it (capacity principle). Further, present agents may need to take up the slack of those individual

\footnotetext{
${ }^{9}$ The difficulty, of course, is that not all GHG emissions, in particular, not all $\mathrm{CO}_{2}$ emissions are harmful. Plants need $\mathrm{CO}_{2}$ to live. But this should not distract from the fact that $\mathrm{CO}_{2}$ emissions above certain levels are harmful (see also Shue 2010).
} 
and collective agents, who through their past actions caused much of the harm in climate change, but who no longer exist.

However, our concern was merely with the more limited problem of whether or not mitigation-related duties are negative or positive. I think that the discussion above shows that we should conceive of them as negative duties. Therefore, even if firms can only hold negative duties, they may still have obligations to reduce their GHG emissions. Let me now turn to the second challenge.

\subsection{Individual Businesses' Actions Make No Difference}

This is a more general challenge, which affects all moral theories according to which the consequences of an action are uniquely relevant for the moral rightness (or wrongness) of that action. It is a particular challenge for defending contributory obligations to aggregate actions or outcomes where individual contributions make no discernible difference to the outcome.

Our moral duties are often thought to be limited by the difference principle: One cannot be morally required to act in a certain way if one's action is not going to make a difference. And indeed, moral principles such as the maximising principle of utility cannot justify obligations to make contributions towards aggregate outcomes where each individual contribution is inconsequential, at least not while the principle of utility is considered an individual action-guiding principle. In other words, the (individualist) maximising principle of utility seems to entail the difference principle.

Note that if the difference principle holds, a counter-intuitive result follows: no individual agent has reason (or a duty) to refrain from their individual contributions to aggregate harm, but at the same time everyone's contributing makes all affected worse off than they could have been. This is the bottom line of what I call collective moral action problems: while everyone does what is morally required of them all end up worse off. Importantly, rule consequentialism and non-consequentialist ethics are largely immune to the problem caused by the difference principle. ${ }^{10}$

In any case, if a general principle of this kind were adopted, our argument that individual business firms have an obligation to mitigate climate change may well be substantially weakened at least for those business firms that could really make no

\footnotetext{
${ }^{10}$ Rule consequentialists need not worry about the difference principle because they consider actions morally wrong or right depending on whether or not they comply with a rule that generates the best consequences. This means that it is the consequences of general rules rather than of individual actions that matter; as long as the general rule (if abided by) makes a difference individual actions need not. Non-consequentialist ethical theories escape the difference-principle dilemma precisely because they do not consider the consequences of an action uniquely decisive for its moral rightness or wrongness. Therefore, the fact that an action does not improve (or worsen) some particular state of affairs is either irrelevant or at least not always decisive, depending on the theory.
} 
significant difference on their own. Yet, there would still be a number of large corporations whose unilateral mitigation efforts may well make a significant difference to the concentration of GHG in the atmosphere.

But should we accept the difference principle? Clearly, there are many problems, which we could successfully address collectively (and arguably should address), even if individually we cannot make a difference towards their solution: climate change mitigation is one of them, but consider also ethical consumption, or the problem of anti-microbial resistance (Jacobsen and Dulsrud 2007; Anomaly 2013; Schwenkenbecher 2014; Lawford-Smith 2015).

Since individualist act-utilitarianism runs into this difficulty when it comes to aggregate harms and other collective action problems, producing highly counterintuitive implications, we have good reason to reject it as a plausible moral theory. This means we have good reasons to reject the difference principle, too.

However, it is not easy to formulate a solid alternative account of moral obligations in the context of collective endeavours and cooperative action. Here is a suggestion made by one of the critics of the difference principle and individualist accounts of moral obligation, Derek Parfit, which runs into the same problem most accounts of collective obligations face, the problem of group knowledge and beliefs. What do individual group members need to know and believe in order for there to be a collective obligation? While I cannot address this issue here in any detail, I discuss Parfit's proposal as one of the first that were made to solve collective moral action problems ${ }^{11}$ :

When (1) the best outcome would be the one in which people are benefited most, and

(2) each of the members of some group could act in a certain way, and

(3) they would benefit these other people if enough of them act in this way, and

(4) they would benefit these people most if they all act in this way, and

(5) each of them both knows these facts and believes that enough of them will act in this way, then

(6) each of them ought to act in this way.... Even if each of them benefits no one, they together can greatly benefit these other people. (1984: 77, my emphasis)

Parfit's suggestion is that duties to contribute to cooperative endeavours can arise even where each contribution makes no difference or benefits no one, to use his words. Rather, we are obligated to contribute where we know that there is an existing cooperative or collective endeavour, which will produce the best outcome out of a range of alternative options. Parfit's argument can address the issue of freeriding on an existing collective good: it explains the wrongness of failing to contribute even if our contribution or lack thereof does not improve or diminish

\footnotetext{
${ }^{11}$ See discussions of the knowledge condition and group beliefs in Harbin, A. (2014). "The Disorientations of Acting against Injustice." Journal of Social Philosophy 45(2): 162-181, Tomalty, J. (2014). "The force of the claimability objection to the human right to subsistence." Canadian Journal of Philosophy 44(1): 1-17, Doan, M. D. (2016). "Responsibility for Collective Inaction and the Knowledge Condition.” Social Epistemology 30(5-6): 532-554.
} 
the good. But it cannot address the problem of individuals' failure to collectively establish a good.

The problem is that, according to Parfit's account, we have obligations to contribute if we know that enough other people will (condition 5). But the difficulty lies in motivating obligations to contribute when there is no certainty as to how others act. Returning to the question of reducing one's carbon footprint, - as a matter of fact-we do not know whether enough other people will act in this way. In fact, we have reason to assume that they will not. We could at this point simply abandon Parfit's suggestion and look for other theories. However, instead I propose to amend his set of conditions.

In principle, there are two potential solutions to the problem that Parfit's conditions pose for our argument concerning obligations to mitigate climate change: a weak and a strong solution. Their availability depends on whether or not the conditions are necessary or merely sufficient. Let me start with the weak solution and then move to the strong solution, which contains the indicated amendment of condition (5).

The claim made by Parfit is a conditional claim. If conditions (1-5) apply then each member of a group has a duty to contribute to the best outcome. If the conditions are sufficient, rather than necessary, we can argue that even if condition (5) - the condition that we believe that enough others will act in the required waydoes not obtain, we may still have obligations to act in the way that collectively produces the best outcome.

Denying the antecedent does not allow us to draw any conclusions concerning the consequent. That is, we-individual and incorporated agents-cannot conclude from the fact that not enough other people reduce their carbon footprint that we have no obligation to reduce ours. In fact, we cannot deduce anything. This is a weak solution, since it does not establish our stronger claim that agents do have an obligation to reduce their carbon footprint even in the absence of certainty about other agents' behaviour.

However, if Parfit's conditions are individually necessary (and jointly sufficient) — and that is what I understand them to be-a failure to have the right beliefs results in a cancellation of the duty to act in a way that is collectively optimal. On Parfit's account, then, individual agents would be excused from contributing to climate change mitigation while there is uncertainty about others' actions.

But perhaps there is another way of defending our claim that individuals and businesses alike have obligations to reduce their carbon footprint even under conditions of uncertainty. One option is to flat out reject the knowledge condition implied in Parfit's account. Felix Pinkert (2014: 194), for instance, has argued that sometimes we can have a joint obligation together with others if it is obvious-or 'salient'-what needs to be done collectively and individually, regardless of whether each of us knows if the other(s) contribute(s). This requires there to be one salient possible collective pattern of actions that would constitute doing what is morally optimal and every relevant agent believing what is in fact her part to be her part. 
Another, less radical, option is the following: instead of demanding that individuals share a belief that others will contribute, we might merely require that each group member (has reason to) believe that if they themselves contribute enough of the others are likely to act in the same way. Returning to our example, individual acts of mitigation may well have no (discernible or morally significant) impact on the overall concentration of GHGs in the atmosphere, but they could well make a difference to other people's actions.

Individual business's carbon footprint reductions are most likely to have an impact on whether other businesses (and individual agents) reduce their carbon footprint if those who implement them are well-known public players and share the information widely. If we follow Parfit, we have an obligation to reduce our carbon footprint only if we know that enough other people reduce theirs. But we need not take other agents' mitigation efforts simply as a given. Not only may our individual contributory actions well influence their willingness to contribute, we can also make an effort to directly persuade them to follow our example.

We should therefore amend Parfit's fifth condition to read:

(5) each of them both knows these facts and believes that enough of them are likely to act in this way if they themselves do.

That is, if one's actions are likely to influence the actions of others, then by our very contribution to solving the collective action dilemma we make it more likely for them to contribute and more likely for the dilemma to be solved.

Again, the greater an agent's potential influence on public opinion and other people's actions, the greater their reason for contributing to a collective endeavour even in the absence of any certainty concerning other agents' contributions. However, such influence may not simply be a given but can be increased by one's own efforts. In other words, there are ways of contributing to the collectively best outcome that make others' compliance more likely. If there is nothing that $I$ can do that makes others more likely to contribute then I may indeed not have an obligation to contribute to what is collectively best (where it is not cost-neutral), at least on this account. However, as I indicated above, more radical solutions such as Pinkert's have been proposed and it may be that reducing the concentration of GHG in the atmosphere is just the kind of collective action where both individual strategies and collective strategy are salient in Pinkert's sense.

The upshot of the preceding discussion is: If firms can be moral agents they can have obligations to refrain from causing avoidable emissions, since these constitute harm. Further, these obligations are not undermined by the fact that individual firms' mitigation efforts often make no direct difference to the total GHG concentration in the atmosphere. They can still make a difference to other agents' actions depending on how they go about making their own contribution. Further, if we follow Pinkert, we might reject the idea that individual agents need to know anything about others' contributions for there to be a collective obligation on them: we could say that a collective obligation exists when it is obvious enough what needs to be done collectively and individually and when this fact itself is publicly known. 


\section{Conclusion}

Having argued that business firms and corporations should be considered moral agents and that their obligations extend beyond duties to shareholders, let me conclude by returning to discussing the extent of their duties to mitigate climate change.

Earlier in the text, I left the following question open: how important are a firm's obligations towards its shareholders or owners compared to their moral obligations towards other agents? This question can now be answered: obligations towards shareholders need not trump negative duties towards all moral agents (though under some circumstances they may). If one accepts that avoidable emissions constitute morally wrongful harm then companies can have stringent obligations to cut those, even at the cost of profit and shareholders' interests. ${ }^{12}$ Note, however, that the preceding discussion establishes pro-tanto, rather than all-out obligations. This means that business firms can have a duty-in principle - to reduce their carbon footprint, but for an individual company this duty may be overridden by more important duties. All-out duties are always sensitive to the specific circumstances (they are all-things-considered duties).

Many business firms will be able to contribute to the reduction of the business's carbon footprint without excessive cost to the business and its shareholders. Businesses can also encourage their employees and customers to reduce their carbon footprint or otherwise mitigate climate change. We can think of energy-saving measures or using renewable energy, promoting the use of public transport for employees, etc. Studies show how companies are already reducing emissions, mostly though in reaction to legislative pressure (Okereke 2007; Eberlein and Matten 2009; Weinhofer and Hoffmann 2010). Øyvind Ihlen (2009) suggests that there is still a lack of radical rethinking among the world's 30 largest corporations. Further, many companies have responded to climate change by trying to undermine a national and global climate consensus and other evasive strategies in order to shirk their responsibilities (van den Hove et al. 2002). Clearly, there is a lot of moral catching up to do.

Let me finish this chapter with a general comment on moral philosophy and business ethics. Ethics, as the study of our values and rules of conduct, cannot bring about change in the world all by itself. But it can point to the assumptions underlying our value-based judgments and expose inconsistencies in our thinking and acting. It does not 'invent' moral rules-morality as norm-based restrictions on (and guidance of) our (inter-)actions is intrinsic to human nature. Philosophical reflection examines existing, ideal and possible codes of conduct and may help

\footnotetext{
${ }^{12}$ On what are considered avoidable emissions see Shue, H. (2010). Deadly Delays, Saving Opportunities: Creating a More Dangerous World? Climate Ethics: Essential Readings. S. M. Gardiner, S. Caney, D. Jamieson and H. Shue. Oxford, Oxford University Press: 146-162.
} 
improve moral thinking. Philosophical ethics forms part of an ongoing public discourse about how we, individual and collective moral agents and moral patients ought to live together. It makes perfect sense for this discourse to include business firms and corporations.

\section{References}

Anomaly J (2013) Collective action and individual choice: rethinking how we regulate narcotics and antibiotics. J Med Ethics 39(4):752-756

Bowie N (2014) Morality, money, and motor cars. In: Hoffman WM, Frederick RE, Schwartz MS (eds) Business ethics: readings and cases in corporate morality. Wiley-Blackwell, Chichester, pp 514-520

Dempsey J (2013) Corporations and non-agential moral responsibility. J Appl Philos 30(4): 334-350

Dietz T, Gardner GT, Gilligan J, Stern PC, Vandenbergh MP (2009) Household actions can provide a behavioral wedge to rapidly reduce US carbon emissions. Proc Nat Sci 106(44): $18452-18456$

Doan MD (2016) Responsibility for collective inaction and the knowledge condition. Soc Epistemol 30(5-6):532-554

Eberlein B, Matten D (2009) Business responses to climate change regulation in Canada and Germany: lessons for MNCs from emerging economies. J Bus Ethics 86(2):241-255

Erskine T (2001) Assigning responsibilities to institutional moral agents: the case of states and quasi-states. Ethics Int Aff 15(2):67-85

Frankena WK (1973) Ethics. Prentice-Hall, Englewood Cliffs

Frederick RE (2014) Ethics in business: two skeptical challenges. In: Hoffman WM, Frederick RE, Schwartz MS (eds) Business ethics: readings and cases in corporate morality. WileyBlackwell, Chichester, pp 192-202

Freeman RE (2014) Stakeholder theory of the modern corporation. In: Hoffman WM, Frederick RE, Schwartz MS (eds) Business ethics: readings and cases in corporate morality. WileyBlackwell, Chichester, pp 184-191

French PA (1984) Collective and corporate responsibility. Columbia University Press, New York Friedman M (1970) The social responsibility of business is to increase its profits. NY Times

Harbin A (2014) The disorientations of acting against injustice. J Soc Philos 45(2):162-181

Ihlen $\varnothing$ (2009) Business and climate change: the climate response of the world's 30 largest corporations. Environ Commun 3(2):244-262

Jacobsen E, Dulsrud A (2007) Will consumers save the world? The framing of political consumerism. J Agric Environ Ethics 20(5):469-482

Lawford-Smith H (2015) Unethical consumption \& obligations to signal. Ethics Int Aff 29(3): 315-330

Lichtenberg J (2010) Negative duties, positive duties, and the "new harms". Ethics 120(3): 557-578

List C, Pettit P (2006) Group agency and supervenience. South J Philos 44(S1):85-105

List C, Pettit P (2011) Group agency: the possibility, design, and status of corporate agents. Oxford University Press, Oxford

Narveson J (2003) The "invisible hand". J Bus Ethics 46(3):201-212

Okereke C (2007) An exploration of motivations, drivers and barriers to carbon management: the UK FTSE 100. Eur Manag J 25(6):475-486

Parfit D (1984) Five mistakes in moral mathematics. Reasons and persons, vol 1. Clarendon Press, Oxford, pp 55-83

Pinkert F (2014) What we together can (be required to) do. Midwest Stud Philos 38(1):187-202 
Schwenkenbecher A (2014) Is there an obligation to reduce one's individual carbon footprint? Crit Rev Int Soc Polit Philos 17(2):168-188

Shue H (2010) Deadly delays, saving opportunities: creating a more dangerous world? In: Gardiner SM, Caney S, Jamieson D, Shue H (eds) Climate ethics: essential readings. Oxford University Press, Oxford, pp 146-162

Smith A (1970 [1776]) The wealth of nations. Books I-III. With an introduction by Andrew Skinner. Penguin, Harmondsworth

Solomon R (1991) Business ethics. In: Singer P (ed) A companion to ethics. Blackwell, Cambridge, pp 354-365

Strand A (2013) Group agency, responsibility, and control. Philos Soc Sci 43(2):201-224

Szigeti A (2014) Collective responsibility and group-control. In: Zahle J, Collin F (eds) Rethinking the individualism-holism debate. Springer, Cham, pp 97-116

Tomalty J (2014) The force of the claimability objection to the human right to subsistence. Can J Philos 44(1):1-17

UNEP (2015) Sixth emissions gap report. UNEP, New York

van den Hove S, Le Menestrel M, de Bettignies H-C (2002) The oil industry and climate change: strategies and ethical dilemmas. Clim Policy 2(1):3-18

Weinhofer G, Hoffmann VH (2010) Mitigating climate change - how do corporate strategies differ? Bus Strateg Environ 19(2):77-89 